\title{
ACL Reconstruction- The Past and the Present
}

\author{
Vikram Khanna* \\ Department of Orthopaedics, Ranjana Hospital, India
}

Submission: January 09, 2017; Published: February 27, 2017

"Corresponding author: Vikram Khanna, Department of Orthopaedics, Ranjana Hospital, 13,D-Road, Allahabad, India, Tel: +91 7073647974; Email: 86.khanna@gmail.com

\section{Abstract}

Anterior Cruciate Ligament (ACL) injury has been the most controversial ligamentous injuries which have been studied in detail for the past 20 years. Knee instability is a disabling clinical problem. Management of ACL injured patients depends on an early diagnosis and adequate treatment. This article deals with the advent and the progression of various techniques of ACL reconstruction.

Keywords: ACL reconstruction; Endobutton; Biointerference screw; Hamstring graft; Bone patella tendon bone graft

\section{Introduction}

Anterior Cruciate Ligament (ACL) injury has been the most controversial ligamentous injuries which have been studied in detail for the past 20 years. ACL is weaker than PCL and hence, torn more commonly [1]. Knee instability is a disabling clinical problem. As ACL doesn't heal on its own it has to undergo reconstruction to restore knee function. ACL restrain the anterior translation of tibia primarily and also restrains the internal rotation of Tibia to a small extent. The mechanism of injury is hyperextension and rotation in knee on a fixed foot.

The effect of the injury varies. On one hand, people live without a functional ACL without significant instability and are referred as "copers" [2]. They can be managed by modification of activity [3]. On the other hand people having recurrent 'giving way' episodes are referred to as a "non-coper", and these patients have to be managed by reconstructive surgery.

Management of ACL injured patients depends on an early diagnosis and adequate treatment. Various methods of ACL reconstruction have been described in the literature which includes a donor autograft (patellar tendon, hamstring tendon or quadriceps tendon) and allograft (Achilles, patellar tendon, hamstring tendon or tibialis anterior) tendons. Other methods which have been tried include using Silver wire [4], Fascia lata [5], and Iliotibial band [6]. More than 400 different methods have been described for ACL repair which include open as well as arthroscopic repair [7]. Most commonly used is the bone- patellar tendon- bone graft. This may disturb the extensor mechanism and hence, hamstrings may be used for the reconstruction. This article deals with the advent and the progression of various techniques of ACL reconstruction.

\section{Historical Background}

In 1806, Bozzini devised the first endoscope illuminated by a candle. 1853 saw the advent of gazogens endocystoscope by Desormaux. Max Nitze in 1876 developed cystoscope using incandescent lamp. Knee joint arthroscopy was first attempted on cadavers by Prof. Kerji Takagi in 1918. The No. 21 arthroscope was released by Dr. Watanabe in 1951.

In 1845, Amedee Bonnet described 3 signs indicating ACL rupture which included a snapping noise, haemarthrosis, and loss of function of knee [8,9]. In 1875, Georges K. Noulis (18491919) described the role of ACL and Noulis described the Lachman test [10].

Mayo Robson [11] was the first to perform cruciate ligament repair in 1895. In 1903 the first ACL replacement was performed by Lange F [12] using semitendinosus which failed. However in 1917, Ernest W Hey [13] Groves was the first surgeon to describe the surgical procedure for ACL tear. In 1935, Willis C [14] Campbell used the medial 1/3 of patella tendon for the repair. In 1939, Harry B [15] Macey used semitendinosus tendon for the repair. In 1963, Kenneth G Jones [16] introduced the 
concept of using a central one-third of patellar tendon graft with an attached patellar bone block, the bone tendon bone graft for the repair of ACL [17].

In 1969, Kurt Franke promoted the use of free bone-tendonbone-graft consisting of one quarter of the patellar tendon and attached patellar and tibial bone blocks. However, this procedure was recommended before cartilage damage and before the age of 50 years. In 1972, MacIntosh DL [18] described a technique using a fascialata graft pedicled on the tibia, then passed under the lateral collateral ligament, and attached to the intramuscular septum (MacIntosh 1-the extra articular MacIntosh). In a subsequent modification (MacIntosh 2), the graft was be brought back intra-articularly (with its weakest portion traversing the joint) and passed into a tibial tunnel.

In 1981, Dandy DJ [19,20] implanted carbon fiber-reinforced ligament substitute, using an arthroscopic procedure with poor results. With carbon fiber going out Dacron and Gore-Tex started being used. However, there was a high rate of synovitis with rupture of the grafts. Hence, this method of repair was abandoned as well. In 1982 Clancy [21] used medial third portion of patellar tendon with a patella bone block. He modified this by detaching the distal end of the graft from tibial tubercle [22]. This was the Bone-Patellar tendon Bone autograft which was considered the gold standard procedure in 1990s [23].

In 1987, Kurusoka M [24] proved the weak link of the construct to be the fixation of the graft with the screws. Bioabsorbable screws using materials like PLA, PGA began to be used. Lipscomb AB et al. [25] found that the maximum strength was achieved with quadrupled semitendinosus tendon autograft [25].

In 1993 Howell SM et al. [26], Tom Rosenberg and Leo Pinczewskiused the pes tendons in three or four strands, and placed the graft in the femoral socket. Pinczewski in his method used an "all-inside" technique, with a large interference screw which was known as the RCI screw. Tom Rosenberg devised fixation with Endo-Button that got locked against the lateral aspect of the femoral condyle [27-31].

\section{Recent outlook}

Leo Chan [32] used quadrupled semitendinosus with endobutton technique found little morbidity with excellent clinical results. Chaudhary D [33] used Bone- Patellar TendonBone and found that anterior knee pain was the most common complication followed by stiffness. Wiliams et al. [34] in 2005 compared the clinical outcomes of a four- strand hamstring tendon and found that this eliminated anterior tibial subluxation in $89 \%$ of patients with a failure rate of $11 \%$ [34].

Goldblatt [35] found that cases with hamstring tendon autograft reported less anterior pain and stiffness. Matsumoto et al. [36] in 2006 compared patellar tendon and hamstring tendon grafts concluded that Bone-hamstring-bone grafts were better than bone-patellar tendon-bone grafts [36]. It was seen that the
BРTВ technique was superior in terms of post-operative laxity and tunnel enlargement. The clinical outcome was better with Hamstring Tendon graft [37].

Pinczewski et al. [38] in a 10year comparative study between hamstring tendon and patellar tendon found that the hamstring tendon autograft was superior. On comparing the morbidity associated with harvesting hamstring tendons it was seen that at the end of the year there was no functional disability [39]. It was seen that in 2010 more than 95\% Hamstring grafts were used for ACL reconstruction [40].

Jung Hwan Lee [41] compared the outcomes of BPTB autograft, Tibialis anterior allograft and Hamstring tendon autograft. It was seen that hamstring tendon autograft group better clinical as well as better second look arthoscopy [41]. Kristian Samuelsson et al. [42] in 2009 in a study concluded that although there were no significant difference between the BPTB and the HS graft functionally but the HS donor site morbidity was less and it was also easier to harvest.

Ahlden M et al. [43] in 2009 tried to analyse knee laxity over time after ACL reconstruction, using BPTB or HS tendon grafts and found that there were no significant differences in knee laxity measurements [43]. Mohtadi et al. [44] in 2011 compared the use of PT and HT grafts and found that they were not able to draw any significant conclusions as PT reconstructions gave more stable knees but were associated with more anterior knee pain [44].

Ralph Akota [42] in 2012 used the quadriceps tendon graft using an anteromedial portal and found that it had the potential advantage of minimum bone loss on the femoral side and graft fixation without implants could be achieved [42]. Barenius Björn in 2012 on evaluating the importance of the time elapsed between the injury and the surgery saw that BPTB grafts were associated with more morbidity and that the reconstruction should be performed within 6 months of the injury. In another study Barenius B et al. [41] in 2013 compared the outcome of semitendinosus graft was harvested alone or with the gracilis. They found that there was no added advantage of harvesting gracilis along with semitendinosus [45].

\section{Current scenario}

Arthroscopy technique is used as the graft can be harvested without violating the joint. It also provides the advantage of cosmetic scars and low morbidity.

The grafts used for ACL reconstruction may be divided into autograts, allografts and synthetic materials. Autograft can be further divided into Patellar tendon; Semitendinosus tendon; semitendinosus/Gracilis tendon; Quadriceps tendon; Plantaris tendon and Iliotibial band. Patellar tendon was widely used was it was considered the Gold standard. This graft constitutes bone plugs from patella and tibial tuberosity. It is associated with a very high incidence of donor site morbidity which is difficult or sometimes impossible to treat. 
As the BPTB graft gives rise to a lot of morbidity the semitendinosus tendon graft is now being used more and more in ACL reconstruction. Even the tensile strength of quadrupled is higher than that of the BPTB graft. The graft of choice currently is the semitendinosus tendon $[46,47]$.

\section{Graft fixation}

The ST graft has mainly 2 advantages over the BPTB graft. Firstly, a quadrupled semitendinous/gracilis have a larger crosssectional area than the patellar tendon grafts. And secondly, smaller bone tunnels are required for the hamstring grafts and hence, the healing is fast and circumferential. Also, recent study of literature shows that there is no difference between hamstring and patellar tendon ACL reconstructions regarding the anterior laxity.

Kouse et al. [42] compared the pullout strength of the fixation devices using the hamstring grafts. They recommended the use of Bone Mulch screw, Endobutton or Rigidfix on the femur side whereas the biointerference screw on the tibial aspect. However, good results don't depend only on graft and fixation but also upon the tunnel positioning. It has been seen that the anterior placement of the tibial or the femoral tunnel can prove detrimental for the graft and may lead to failure of the reconstruction [48].

Howell and Clark in 1992 found that tibial tunnels which were located within 37\%-47\% were impingement free. Linter in 1996 cadaveric study found that the ideal center for intact ACL tibial insertion was $40 \%$ from the anterior end of the tibial articular surface. This value was found to be $41 \%$ in a MRI based cadaveric study by Stilubli and Rauschning's in 1994.

Merchant et al. [48] in 2001 did a study to determine the best placement of the tibial tunnel for ACL reconstruction and found that the best placement of the tunnel was achieved by an endoscopic single incision utilizing a guide keying on the PCL for achievement of posterior tibial tunnel location [48].

Pretensioning of the graft provides better alignment of the graft however, excessive tensioning may cause "capture" of the joint and this may result in difficulty in regaining full range of motion and also leads to degeneration of the joint.

\section{Conclusion}

Although the ACL reconstruction has been marred with controversies with the literature divided on many accounts but still with the advent of latest studies have made it an evidence based procedure with comparable results. Even though, the graft strength and the fixation techniques play an important role in the clinical outcome but the mainstay in the ACL reconstruction is the tunnel placement and should be taken care for.

\section{References}

1. Nordenvall R, Bahmanyar S, Adami J, Stenros C, Wredmark T, et al. (2012) A population-based nationwide study of cruciate ligament injury in sweden, 2001-2009: incidence, treatment, and sex differences. Am J Sports Med 40(8): 1808-1813.
2. Kostogiannis I, Ageberg E, Neuman P, Dahlberg L, Friden T, et al. (2007) Activity level and subjective knee function 15 years after anterior cruciate ligament injury: a prospective, longitudinal study of nonreconstructed patients. Am J Sports Med 35(7): 1135-1143.

3. Engstrom B, Gornitzka J, Johansson C, Wredmark T (1993) Knee function after anterior cruciate ligament ruptures treated conservatively. IntOrthop 17(4): 208-213.

4. Corner EM (1914) The exploration of the knee joint: with some illustrative cases. Br J Surg 2(6): 191-204.

5. Hey-Groves EW (1920) The crucial ligaments of the knee joint: Their function, rupture and the operative treatment of the same. Br J surg 7: 505-515.

6. Smith A (1918) The diagnosis and treatment of injuries of crucial ligaments. Br J Surg 6: 176-189.

7. Strobel MJ (Ed.) Anterior cruciate ligament. (1988) In: Textbook of manual of arthroscopic surgery. ( $1^{\text {st }}$ edn.), Heidelberg Berlin. SpringerVerlag, p. 67-69.

8. Bonnet $A(1853)$ Traite des maladies articularis ( $2^{\text {nd }}$ edn). Bailliere Paris, USA, pp. 354-357.

9. Bonnet A (1845) Traite des maladies des articularisvol $1 \& 2$ Avec atlas. Bailliere Paris, USA.

10. Robert H Miller (2008) Knee injuries; In Campbell's Operative Orthopaedics. (11 ${ }^{\text {th }}$ edn), Mosby Elsevier Philadelphia, USA.

11. Mayo Robson AW (1903) Ruptured cruciate ligaments and their repair by operation. Ann Surg 37(5): 716-718.

12. Lange F (2016) Uber die Schnenplastik. Verh Dtsch Orthop Ges 2: 1012.

13. Hey Groves EW (1979) Operation for the repair of cruciate ligament. Lancet 2: 674-675.

14. Campbell WC (1963) Repair of the ligaments of the knee: report of a new operation for the repair of the anterior cruciate ligament. Surg Gynecol Obstet 62: 964-968.

15. Macey HB (1939) A new operative procedure for repair of ruptured cruciate ligament of the knee joint. Surg Gynecol Obstet 69: 108-139.

16. Jones KG (1970) Reconstruction of the anterior cruciate ligament using the central one third of the patellar ligament- a follow-up report. J Bone Join Surg 52(7): 1302-1308.

17. Jones KG (1963) Reconstruction of the anterior cruciate ligament. A technique using the central one third of the patellar ligament. J Bone Join Surg 45: 925-932.

18. Lemaire M (1975) Instabilitechronique du genou:technique et resultants des plastiesligamentaires en traumatologie sportive. J Chir (Paris) 110: 281-294.

19. Cho KO (1975) Reconstruction of the anteriorcruciate ligament by semitendinosus tenodesis. J Bone Join Surg 57(5): 608-612.

20. Dandy DJ, Flanagan JP, Steemeyer V (1982) Arthroscopy and the management of the ruptured anterior cruciate ligament. ClinOrthop 167: $43-49$

21. Clancy WG (1982) Arthroscopic anterior cruciate ligament reconstruction using one third patellar ligament augmented by extra articular tendon transfers. J Bone Joint Surg 64A: 352-359.

22. Clancy WG (1988) Arthroscopic anterior cruciate ligament reconstructions with patellar tendon. Tech. Orthop 2: 4.

23. Clancy WG, Smith L (1991) Arthroscopic anterior and posterior cruciate ligament reconstruction technique. Ann Chir Gynaecol 80(2): 141-148. 
24. Kurosaka M, Yoshiya S, Andrish IT (1987) A biomechanical comparison of different surgical techniques of graft fixation in anterior cruciate ligament reconstruction. Am J Sports Med 15(3): 225-229.

25. Lipscomb AB, Jonhston RK, Synder RB (1982) Evaluation of hamstring strength following use of semitendinosus and gracilis tendons to reconstruct anterior cruciate ligament. Am J Sports Med 10(6): 340342 .

26. Howell SM (1993) Arthroscopically assisted technique for preventing roof impingement of anterior cruciate ligament graft illustrated by the use of an autogenousdoublelooped semitendinosus and gracilis graft Operative tech in Sports Medicine 1(1): 58-65.

27. Rosenberg TD (1993) Technique for endoscopic method of ACL reconstruction Technical Bulletin Mansfield MA. Acufex Microsurgical.

28. Pflaster D (1994) Pull out strength- Pinczewski endoscopic hamstring technique utilizing the RCI anterior cruciate ligament fixation screw. Biomechanics Research Laboratory Smith and Nephew Donjoy 1994.

29. Pinczewski L (1997) Two year results of endoscopic reconstruction of isolated ACL ruptures with quadruple hamstring tendon autograft and interference screw fixation. AAOS Annu Meet San Francisco, CA, USA

30. Pinczewski L, Clingeleffer AJ, Otto DD (1997) Integration of hamstring tendon graft with bone in reconstruction of the anterior cruciate ligament. Arthroscopy 13(5): 641-643.

31. Pinczewski L, Thuresson P, Otto DD, Nyquist F (1997) Arthroscopic posterior cruciate ligament reconstruction using four strand hamstring tendon graft and interference screws. Arthroscopy 13(5): 661-665.

32. Chen L, Cooley V, Rosenberg T (2003) ACL reconstruction with hamstring tendon. Orthopclin N Am 34: 9-18.

33. Chaudhary D, Monga P, Joshi D, Easwaran R, Bhatia N, et al. (2005) Arthroscopic reconstruction of anterior cruciate ligament using BonePatellar Tendon-Bone autograft: Experience of first 100 cases. J Ortho Surg 13(2): 147-152.

34. Williams, Riley J, Hyman, Jon MD, Petrigliano, et al. (2005) Anterior Cruciate Ligament Reconstruction with a four strand hamstring tendon autograft. J Bone Join Surg March 87-A (2): 225-232.

35. Goldblatt JP, Fitzsimmons SE, Balk E, Richmond JC (2005) Reconstruction of the anterior cruciate ligament:Meta analysis of Patellar Tendon versus Hamstring Tendon autograft. Arthroscopy 21(7): 791-803.

36. Matsumoto A, Yoshiya S, Muratsu H, Yagi M, Iwasaki Y, et al. (2006) A comparison of bone-patellar tendon-bone and bone-hamstring tendon-bone autografts for anterior cruciate ligament reconstruction. Am J Sports Med 34(2): 213-219.
37. Congress of French Society for Arthoscopy Paris 1999.

38. Pinczewski LA, Lyman J, Salmon LJ, Russell VJ, Roe J, et al. (2007) A 10year comparison of anterior cruciate ligament reconstruction with Hamstring tendon and Patellar tendon autograft: A controlled, prospective trial. Am J Sports Med 35(4): 564-574.

39. Yasuda (1995) Anterior cruciate ligament reconstruction using hamstring tendon graft. Am J Sports Med 3(6): 706-709.

40. Ahldén M, Samuelsson K, Sernert N, Forssblad M, Karlsson J, et al. (2012) The Swedish National Anterior Cruciate Ligament Register: a report on baseline variables and outcomes of surgery for almost 18,000 patients. Am J Sports Med 40(10): 2230-2235.

41. Jung Hwan Lee, Dae Kyung Bae, Sang Jun Song, Seung Mokcho, Kyoung Ho Yoon (2010) Comparison of clinical results and second look arthroscopy findings after arthroscopic ACL Reconstruction using three different types of grafts. Arthroscopy 26 (1): 41-49.

42. Samuelsson K, Andersson D, Karlsson J (2009) Treatment of anterior cruciate ligament injuries with special reference to graft type and surgical technique: an assessment of randomized controlled trials. Arthroscopy 25(10): 1139-1174.

43. Ahldén M, Kartus J, Ejerhed L, Karlsson J, Sernert N (2009) Knee laxity measurements after anterior cruciate ligament reconstruction, using either bone-patellar-tendon-bone or hamstring tendon autografts, with special emphasis on comparison over time. Knee Surg Sports TraumatolArthrosc 17(9): 1117-11124.

44. Mohtadi NG, Chan DS, Dainty KN, Whelan DB (2011) Patellar tendon versus hamstring tendon autograft for anterior cruciate ligament rupture in adults. Cochrane Database Syst Rev 7(9): CD005960.

45. Björn Barenius, Kate E Webster, Jodie Mc Clelland, Julian A (2013) Hamstring tendon anterior cruciate ligament reconstruction: does gracilis tendon harvest matter? Int Orthop 37(2): 347.

46. Woo SL, Hollis JM, Adams DJ, Lyon RM, Takai S (1991) Tensile Properties of the Human femur-anterior cruciate ligament-tibia complex. Am J Sports Medicine 29: 217-25.

47. Schatzman L, Brunner P, Staubli H (1998) Effect of cyclic preconditioning on the tensile properties of human quadriceps tendons and patellar ligaments. Knee Surgery Sports Traumatology Arthroscopy 6(Suppl 1): 56-61.

48. Thomas C, Merchant MD (2001) Comparison of three patellar tendon anterior cruciate ligament reconstruction techniques with emphasis on tunnel location and outcome. Are our results improving? The Iowa Orthop J 21: 25-30.

\section{Your next submission with Juniper Publishers will reach you the below assets}

- Quality Editorial service

- Swift Peer Review

- Reprints availability

- E-prints Service

- Manuscript Podcast for convenient understanding

- Global attainment for your research

- Manuscript accessibility in different formats

( Pdf, E-pub, Full Text, Audio)

- Unceasing customer service

Track the below URL for one-step submission

https://juniperpublishers.com/online-submission.php 